\title{
Combined effect of hypertension and hyperuricemia on ischemic stroke in a rural Chinese population
}

\author{
Peng Sun ${ }^{1 \dagger}$, Mengqi Chen ${ }^{2 \dagger}$, Xiaofan Guo ${ }^{2 *}$, Zhao Li ${ }^{2}$, Ying Zhou ${ }^{2}$, Shasha Yu ${ }^{2}$, Hongmei Yang ${ }^{2}$, Guozhe Sun ${ }^{2}$, \\ Liqiang Zheng ${ }^{3}$ and Yingxian Sun ${ }^{2}$
}

\begin{abstract}
Background: To investigate the combined effect of hypertension and hyperuricemia to the risk of ischemic stroke in a rural Chinese population.

Methods: The cross-sectional study was conducted from 2012 to 2013 in a rural area of China. After exclusion for missing data, we finally included 11,731 participants into analysis.

Results: After adjusting for age, current smoking, current drinking, BMI, TG, HDL-C and eGFR, hypertension was significantly associated with ischemic stroke in men (OR: 2.783, 95\% Cl: 1.793, 4.320) and in women (OR: 4.800, 95\% Cl: $2.945,7.822)$. However, hyperuricemia was significantly associated with ischemic stroke only in women (OR: $1.888,95 \%$ Cl: 1.244, 2.864). After full adjustment, participants with both hypertension and hyperuricemia had 8.9 times higher risk than those without them. Finally, the interaction between hypertension and hyperuricemia was statistically significant only in women rather than in men after full adjustment.

Conclusions: This study demonstrated the positive correlations between hypertension, hyperuricemia and ischemic stroke. Our study also demonstrated the joint effect between hypertension and hyperuricemia towards ischemic stroke only in women, not in men.
\end{abstract}

Keywords: Hypertension, Hyperuricemia, Ischemic stroke

\section{Background}

Globally, stroke is a major cause of death and adult disability [1]. By 2013, 27 of China's 33 provinces had stroke as the main cause of death [2]. In China, the annual stroke mortality rate is about 1.6 million people, which is about 157 deaths per 100,000 people due to stroke [3]. Among 100,000 people, strokes caused about 116 deaths in urban areas and 111 deaths in rural areas

\footnotetext{
* Correspondence: guoxiaofan1986@hotmail.com

${ }^{+}$Peng Sun and Mengqi Chen contributed equally to this work.

${ }^{2}$ Department of Cardiology, the First Hospital of China Medical University,

155 Nanjing North Street, Heping District, Shenyang 110001, Liaoning, China Full list of author information is available at the end of the article
}

[3]. Therefore, stroke has emerged as a major health problem in China.

Hypertension (HTN) is one of the important risk factors of stroke. More than $60 \%$ of acute stroke patients had elevated blood pressure [4]. Furthermore, more than $70 \%$ of stroke patients had a history of hypertension, and nearly half of them had poor baseline blood pressure control [5-7]. The incidence of stroke increased proportionally with the increase in systolic and diastolic blood pressure, with a 3.1-fold increase in the relative risk for men and a 2.9-fold increase in women [8, 9]. Hyperuricemia is another potential important risk factor of stroke. The elevated level of serum uric acid was independently positively correlated with ischemic stroke in

C C The Author(s). 2021 Open Access This article is licensed under a Creative Commons Attribution 4.0 International License, which permits use, sharing, adaptation, distribution and reproduction in any medium or format, as long as you give appropriate credit to the original author(s) and the source, provide a link to the Creative Commons licence, and indicate if changes were made. The images or other third party material in this article are included in the article's Creative Commons licence, unless indicated otherwise in a credit line to the material. If material is not included in the article's Creative Commons licence and your intended use is not permitted by statutory regulation or exceeds the permitted use, you will need to obtain permission directly from the copyright holder. To view a copy of this licence, visit http://creativecommons.org/licenses/by/4.0/ The Creative Commons Public Domain Dedication waiver (http://creativecommons.org/publicdomain/zero/1.0/) applies to the data made available in this article, unless otherwise stated in a credit line to the data. 
patients with aged $<60$ years [10]. Previous prospective observational studies have showed that hyperuricemia was independently correlated with stroke incidence and mortality [11, 12]. On the other hand, hyperuricemia was also associated with hypertension, type 2 diabetes, dyslipidemia, chronic kidney disease, and cardiovascular events, particularly stroke [13-15].

Previous studies have clarified the potential correlation between hypertension, hyperuricemia and ischemic stroke. However, these studies only examined the independent effects of risk factors. So far, no studies have investigated the combined effect of hypertension and hyperuricemia to ischemic stroke. Thus, this study aimed to investigate the combined effect of HTN and hyperuricemia to the risk of ischemic stroke.

\section{Methods}

\section{Study population}

The present study was based on a cross-sectional epidemiological survey known as NCRCHS which conducted from January 2012 to August 2013. The detailed design and rationale of NCRCHS were fully discussed elsewhere [16]. A total number of 11,956 participants (age $\geq 35$ years) were collected from Liaoning province, northeastern China. In the present work, 225 participants were further excluded for missing data. Eventually, 11,731 subjects were enrolled into the present work. Our study was approved by the Ethics Committee of China Medical University (Shenyang, China). All subjects provided written informed consent.

\section{Data collection and measurements}

The process about data collection and measurements was fully described in our previously published studies [17]. Before the survey, cardiologists and nurses participated a professional training, passed a standardized exam, and acquired the qualification to gather data. The data were collected through uniform questionnaires regarding demographic data, anthropometric parameters, health-related behaviors. The central steering committee with a subcommittee conducted the quality assurance process of data collection. The questionnaire was designed to collect detail information from participants. Smoking and drinking status were separated into current status and others according to participants' self-reports. After participants rested for at least five minutes in a properly relaxed and sitting state, the blood pressure was taken three times and measured by two randomly selected workers. The mean reading of three consecutive values was determined as the final result of blood pressure. Before the measurement of anthropometric indices, lightweight clothes without shoes were required for the subjects. The weight of participants was quantified to $0.1 \mathrm{~kg}$ by calibrated digital scales and height was quantified to $0.1 \mathrm{~cm}$ by portable stadiometers. After individuals were fasting at least $12 \mathrm{~h}$, blood samples were collected from the antecubital veins in the morning. For long-term storage, the serum of venous blood sample was isolated by calibrated centrifuge and frozen at $20^{\circ} \mathrm{C}$. The fasting blood samples of individuals were tested by Olympus AU640 auto analyzers to measure the blood concentrations of FPG, TG, HDL-C, Scr and SUA.

\section{Definition}

The body mass index (BMI) was determined as: weight $(\mathrm{kg}) /$ height $\left(\mathrm{m}^{2}\right)$. The estimated glomerular filtration rate (eGFR) was defined according to the CKD-EPI equation [18]. The definition of hyperuricemia was serum uric acid (SUA) $\geq 357 \mu \mathrm{mol} / \mathrm{L}$ for females and $\geq 417 \mu \mathrm{mol} / \mathrm{L}$ for males [19]. Hypertension was determined as systolic blood pressure $(\mathrm{SBP}) \geq 140 \mathrm{mmHg}$ and/or diastolic blood pressure (DBP) $\geq 90 \mathrm{mmHg}$ [20]. Ischemic stroke was determined as a history of cerebrovascular events, which was demonstrated by either cranial CT or MR scan within the past 2 years.

\section{Statistical analysis}

The results were displayed as mean values \pm standard deviation (SD) or median (interquartile) for continuous variables. The following category variables were presented as frequencies (percentages). Students' t-test or MannWhitney test was applied to compare continuous variables between groups. The chi-square test was performed to compare category variables between groups. Additionally, the rank-sum test was used to compare ordinal category variables between groups. Multivariate logistic regression analyses were performed to evaluate the relationship of hypertension and hyperuricemia to ischemic stroke. The results were displayed as odds ratio (OR) and 95\% confidence interval $(95 \% \mathrm{CI})$. All of the analyses were performed by SPSS 25.0 software (IBP corp). A two-tailed $P$ value $<0.05$ was considered as significant.

\section{Results}

Table 1 shows the characteristics of study population divided by ischemic stroke and sex. The prevalence of ischemic stroke was $3.16 \%$ in men and $3.12 \%$ in women. Population with ischemic stroke had higher age, SBP and DBP in both sexes, and had higher BMI, TG and SUA only in women. The percentage of current smoking and current drinking was dramatically lower in patients group than those in normal group in both sexes. The percentage of hyperuricemia was higher only in women and hypertension was higher in both genders. As shown in Fig. 1, the prevalence of ischemic stroke was greater in HTN $(+)$ and HUA $(+)$ in both gender than in HTN $(-)$ and HUA (-) $(0.9 \%$ vs. $5.2 \%$ for male; $0.6 \%$ vs. $12.5 \%$ for female). 
Table 1 Characteristics of study population divided by ischemic stroke and sex

\begin{tabular}{|c|c|c|c|c|c|c|}
\hline & Men & & & Women & & \\
\hline & Ischemic strok & & & Ischemic strok & & \\
\hline & No $(n=5206)$ & Yes $(n=170)$ & $p$ value & No $(n=6104)$ & Yes $(n=197)$ & $p$ value \\
\hline Age (years) & $54.0 \pm 10.7$ & $63.7 \pm 9.1$ & $<0.001$ & $53.1 \pm 10.3$ & $62.9 \pm 8.2$ & $<0.001$ \\
\hline Current smoking (\%) & $3000(57.0)$ & $81(47.6)$ & 0.015 & $1002(16.4)$ & $30(15.2)$ & 0.658 \\
\hline Current drinking (\%) & $2405(45.7)$ & $44(25.9)$ & $<0.001$ & $183(3.0)$ & $0(0.0)$ & 0.014 \\
\hline $\mathrm{BMI}\left(\mathrm{kg} / \mathrm{m}^{2}\right)$ & $24.7 \pm 3.5$ & $25.0 \pm 3.4$ & 0.362 & $24.8 \pm 3.8$ & $26.0 \pm 3.7$ & $<0.001$ \\
\hline FPG $(\mathrm{mmol} / \mathrm{L})$ & $5.6(5.2-6.1)$ & $5.8(5.4-6.4)$ & $<0.001$ & $5.5(5.1-6.0)$ & $5.7(5.3-6.7)$ & $<0.001$ \\
\hline $\mathrm{TC}(\mathrm{mmol} / \mathrm{L})$ & $5.2 \pm 1.0$ & $5.2 \pm 1.0$ & 0.586 & $5.3 \pm 1.1$ & $5.6 \pm 1.0$ & $<0.001$ \\
\hline TG $(\mathrm{mmol} / \mathrm{L})$ & $1.2(0.9-1.9)$ & $1.4(1.0-2.1)$ & 0.055 & $1.2(0.9-1.9)$ & $1.9(1.2-2.8)$ & $<0.001$ \\
\hline $\mathrm{HDL}-\mathrm{C}(\mathrm{mmol} / \mathrm{L})$ & $1.4 \pm 0.4$ & $1.3 \pm 0.4$ & 0.012 & $1.4 \pm 0.3$ & $1.3 \pm 0.3$ & $<0.001$ \\
\hline LDL-C (mmol/L) & $2.9 \pm 0.8$ & $3.0 \pm 0.8$ & 0.004 & $3.0 \pm 0.8$ & $3.3 \pm 0.8$ & $<0.001$ \\
\hline eGFR (ml/min/1.73 m²) & $94.5 \pm 15.3$ & $85.5 \pm 15.3$ & $<0.001$ & $92.4 \pm 16.1$ & $82.6 \pm 18.7$ & $<0.001$ \\
\hline $\mathrm{SBP}(\mathrm{mmHg})$ & $143.2 \pm 22.2$ & $159.8 \pm 26.9$ & $<0.001$ & $139.5 \pm 23.6$ & $161.3 \pm 27.4$ & $<0.001$ \\
\hline $\mathrm{DBP}(\mathrm{mmHg})$ & $83.6 \pm 11.8$ & $87.7 \pm 11.8$ & $<0.001$ & $80.4 \pm 11.5$ & $85.8 \pm 12.2$ & $<0.001$ \\
\hline SUA $(\mu \mathrm{mol} / \mathrm{L})$ & $333.3 \pm 83.0$ & $344.4 \pm 97.5$ & 0.088 & $254.6 \pm 66.7$ & $289.8 \pm 88.6$ & $<0.001$ \\
\hline Hyperuricemia (\%) & 779 (14.8) & $33(19.4)$ & 0.098 & $432(7.1)$ & $41(20.8)$ & $<0.001$ \\
\hline Hypertension (\%) & $2787(53.0)$ & $143(84.1)$ & $<0.001$ & $2889(47.3)$ & $177(89.8)$ & $<0.001$ \\
\hline Anti-hypertensive drug & $612(11.6)$ & $89(52.4)$ & $<0.001$ & $956(15.6)$ & $127(64.5)$ & $<0.001$ \\
\hline
\end{tabular}

Data are expressed as mean \pm standard deviation (SD) or median (interquartile range) and numbers (percentage) as appropriate

Abbreviations: BMI body mass index, FPG fasting plasma glucose, TC total cholesterol, TG triglyceride, HDL-C high-density lipoprotein cholesterol, $L D L-C$ lowdensity lipoprotein cholesterol, eGFR estimated glomerular filtration rate, SBP systolic blood pressure, DBP diastolic blood pressure, SUA serum uric acid

Logistic regression was performed to display the association of SBP, DBP and SUA with ischemic stroke by sex (Table 2). After adjusting for age, current smoking, current drinking, BMI, FPG, TC, TG, HDL-C, LDL-C and eGFR, SBP was significantly associated with ischemic stroke in men (OR: 1.017, 95\% CI: 1.011, 1.024) and in women (OR: 1.018, 95\% CI: 1.013, 1.024). Similarly, DBP and SUA was significantly associated with ischemic stroke in both men and women.

Multivariate logistic regression was performed to reveal the association of hypertension and hyperuricemia with ischemic stroke by sex (Table 3). After adjusting for age, current smoking, current drinking, BMI, FPG, TC, TG, HDL-C, LDL-C and eGFR, hypertension was significantly associated with ischemic stroke in men (OR: 2.783, 95\% CI: $1.793,4.320$ ) and in women (OR: 4.800, 95\% CI: $2.945,7.822)$. However, hyperuricemia was significantly associated with ischemic stroke only in women (OR: 1.888, 95\% CI: 1.244, 2.864).

Table 4 shows logistic regression of the joint effect of hypertension and hyperuricemia for ischemic stroke by sex. Participants without both hypertension and

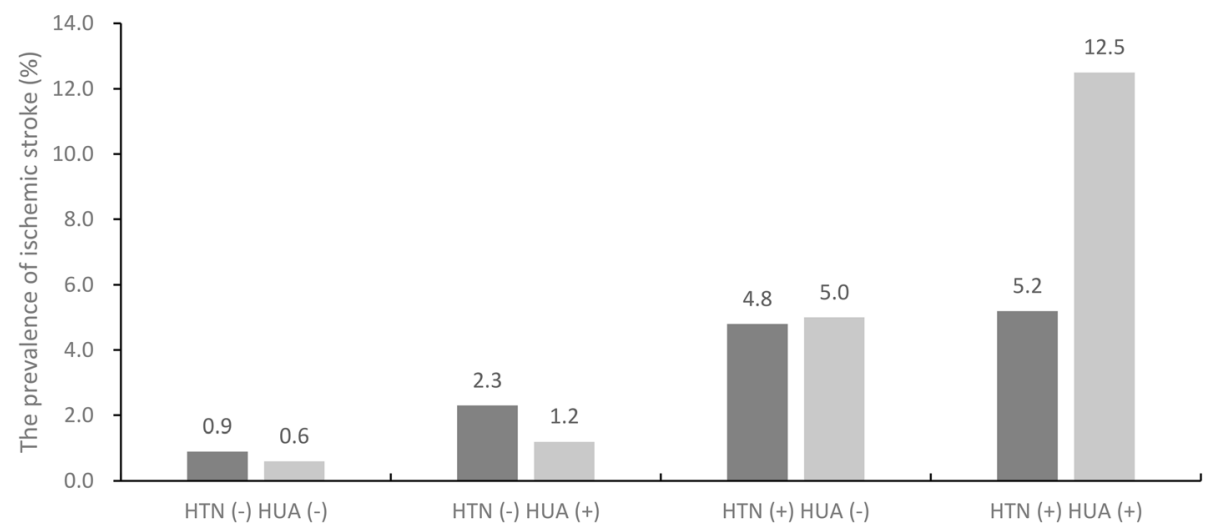

Fig. 1 Prevalence of ischemic stroke according to the hypertension and hyperuricemia stratified by sex 
Table 2 Multivariate logistic regression of SBP, DBP and SUA for ischemic stroke by sex

\begin{tabular}{|c|c|c|c|c|c|c|}
\hline & \multicolumn{6}{|l|}{ Odds Ratio $(95 \% \mathrm{Cl})$} \\
\hline & Model 1 & $P$ value & Model 2 & $P$ value & Model 3 & $P$ value \\
\hline \multicolumn{7}{|l|}{ Men } \\
\hline SBP & $1.027(1.021,1.033)$ & $<0.001$ & $1.020(1.013,1.026)$ & $<0.001$ & $1.017(1.011,1.024)$ & $<0.001$ \\
\hline DBP & $1.027(1.015,1.039)$ & $<0.001$ & $1.035(1.022,1.048)$ & $<0.001$ & $1.032(1.018,1.045)$ & $<0.001$ \\
\hline SUA & $1.002(1.000,1.003)$ & 0.087 & $1.002(1.001,1.004)$ & 0.008 & $1.002(1.000,1.004)$ & 0.032 \\
\hline \multicolumn{7}{|l|}{ Women } \\
\hline SBP & $1.030(1.025,1.035)$ & $<0.001$ & $1.021(1.016,1.027)$ & $<0.001$ & $1.018(1.013,1.024)$ & $<0.001$ \\
\hline $\mathrm{DBP}$ & $1.037(1.025,1.048)$ & $<0.001$ & $1.035(1.023,1.047)$ & $<0.001$ & $1.028(1.016,1.040)$ & $<0.001$ \\
\hline SUA & $1.006(1.005,1.008)$ & $<0.001$ & $1.004(1.002,1.006)$ & $<0.001$ & $1.003(1.000,1.005)$ & 0.018 \\
\hline
\end{tabular}

Model 1: no adjust

Model 2: adjust for age, current smoking, current drinking

Model 3: adjust for age, current smoking, current drinking, BMI, FPG, TC, TG, HDL-C, LDL-C, eGFR

Abbreviations: $B M I$ body mass index, FPG fasting plasma glucose, $T C$ total cholesterol, $T G$ triglyceride, $H D L-C$ high-density lipoprotein cholesterol, $L D L-C$ low-

density lipoprotein cholesterol, eGFR estimated glomerular filtration rate, SBP systolic blood pressure, DBP diastolic blood pressure, SUA serum uric acid

hyperuricemia were defined as the reference group. For men, participants with hypertension and hyperuricemia had 5.9 times higher risk of ischemic stroke than those without them in model 1. After adjusting for age, current smoking, current drinking, BMI, FPG, TC, TG, HDL-C, LDL-C and eGFR (model 3), participants with both of them had 4.1 times higher risk than those without them in men. For women, participants with hypertension and hyperuricemia had 24.3 times higher risk of ischemic stroke than those without them in model 1 . After full adjustment of covariates, participants with both of them had 8.9 times higher risk than those without them. Finally, the interaction between hypertension and hyperuricemia was statistically significant only in women rather than in men after full adjustment.

\section{Discussion}

This study demonstrated the independent and positive correlations between hypertension, hyperuricemia and ischemic stroke in a rural Chinese population. More importantly, our study for the first time implicated the joint effect between hypertension and hyperuricemia towards ischemic stroke only in women, not in men. Our results suggest the joint effect of hypertension and hyperuricemia on ischemic stroke in women may be greater than the sum of their individual effects. Therefore, our research may provide a simple explanation for the public to understand the harm of hypertension and hyperuricemia on ischemic stroke.

In this study, hypertension was positively associated with the risk of ischemic stroke in both men and women, which was consistent with previous studies [2123]. For a long time, elevated blood pressure has been associated with cardiovascular outcomes, and the correlation between hypertension and increased risk of stroke may be the strongest and easiest to recognize. Previous randomized controlled trials have suggested that lowering high blood pressure was positive treatment in patients with acute ischemic stroke [24, 25]. Evidence has

Table 3 Multivariate logistic regression of hypertension and hyperuricemia for ischemic stroke by sex

\begin{tabular}{|c|c|c|c|c|c|c|}
\hline & \multicolumn{6}{|l|}{ Odds Ratio $(95 \% \mathrm{Cl})$} \\
\hline & Model 1 & $P$ value & Model 2 & $P$ value & Model 3 & $P$ value \\
\hline \multicolumn{7}{|l|}{ Men } \\
\hline Hypertension & $4.700(3.104,7.116)$ & $<0.001$ & $3.245(2.119,4.969)$ & $<0.001$ & $2.783(1.793,4.320)$ & $<0.001$ \\
\hline Hyperuricemia & $1.386(0.940,2.042)$ & 0.099 & $1.627(1.092,2.424)$ & 0.017 & $1.431(0.919,2.230)$ & 0.113 \\
\hline \multicolumn{7}{|l|}{ Women } \\
\hline Hypertension & $9.849(6.186,15.680)$ & $<0.001$ & $5.933(3.680,9.566)$ & $<0.001$ & $4.800(2.945,7.822)$ & $<0.001$ \\
\hline Hyperuricemia & $3.451(2.413,4.934)$ & $<0.001$ & $2.529(1.748,3.661)$ & $<0.001$ & $1.888(1.244,2.864)$ & 0.003 \\
\hline
\end{tabular}

Model 1: no adjust

Model 2: adjust for age, current smoking, current drinking

Model 3: adjust for age, current smoking, current drinking, BMI, FPG, TC, TG, HDL-C, LDL-C, eGFR

Abbreviations: BMI body mass index, FPG fasting plasma glucose, TC total cholesterol, $T G$ triglyceride, $H D L-C$ high-density lipoprotein cholesterol, $L D L-C$ low-

density lipoprotein cholesterol, eGFR estimated glomerular filtration rate 
Table 4 Multivariate logistic regression of the joint effect of hypertension and hyperuricemia for ischemic stroke by sex

\begin{tabular}{|c|c|c|c|c|c|c|}
\hline & \multicolumn{6}{|l|}{ Odds Ratio $(95 \% \mathrm{Cl})$} \\
\hline & Model 1 & $P$ value & Model 2 & $P$ value & Model 3 & $P$ value \\
\hline \multicolumn{7}{|l|}{ Men } \\
\hline HTN (-) HUA (-) & 1 (reference) & & 1 (reference) & & 1 (reference) & \\
\hline HTN (-) HUA (+) & $2.516(1.055,6.000)$ & 0.037 & $3.133(1.299,7.556)$ & 0.011 & $2.890(1.173,7.121)$ & 0.021 \\
\hline HTN (+) HUA (-) & $5.498(3.409,8.866)$ & $<0.001$ & $3.777(2.317,6.157)$ & $<0.001$ & $3.296(1.998,5.437)$ & $<0.001$ \\
\hline HTN (+) HUA (+) & $5.917(3.276,10.688)$ & $<0.001$ & $4.827(2.642,8.819)$ & $<0.001$ & $4.059(2.126,7.751)$ & $<0.001$ \\
\hline$P$ value for interaction & & 0.007 & & 0.011 & & 0.073 \\
\hline \multicolumn{7}{|l|}{ Women } \\
\hline HTN (-) HUA (-) & 1 (reference) & & 1 (reference) & & 1 (reference) & \\
\hline HTN (-) HUA (+) & $2.136(0.491,9.284)$ & 0.312 & $1.694(0.387,7.421)$ & 0.484 & $1.353(0.306,5.991)$ & 0.691 \\
\hline HTN (+) HUA (-) & $8.956(5.465,14.677)$ & $<0.001$ & $5.492(3.309,9.114)$ & $<0.001$ & $4.592(2.740,7.696)$ & $<0.001$ \\
\hline HTN (+) HUA (+) & $24.254(13.688,42.976)$ & $<0.001$ & $12.689(7.027,22.912)$ & $<0.001$ & $8.913(4.726,16.809)$ & $<0.001$ \\
\hline$P$ value for interaction & & $<0.001$ & & $<0.001$ & & $<0.001$ \\
\hline
\end{tabular}

Model 1: no adjust

Model 2: adjust for age, current smoking, current drinking

Model 3: adjust for age, current smoking, current drinking, BMI, FPG, TC, TG, HDL-C, LDL-C, eGFR

Abbreviations: BMI body mass index, FPG fasting plasma glucose, $T C$ total cholesterol, $T G$ triglyceride, $H D L-C$ high-density lipoprotein cholesterol, $L D L-C$ lowdensity lipoprotein cholesterol, eGFR estimated glomerular filtration rate

shown that $80 \%$ of patients with acute ischemic stroke have hypertension, which is independently associated with poor prognosis [26-28].

Uric acid is a product of human purine metabolism and is known to be related to many risk factors for strokes, such as high blood pressure, obesity, and diabetes $[13,15,29]$. In our study, elevated uric acid was also positively associated with the risk of ischemic stroke but only in women. Consistently, the Rotterdam Study showed that elevated uric acid was a positive risk factor for stroke only in women [30]. However, some previous studies revealed the correlation between hyperuricemia and stroke in both men and women, though stronger in women than in men $[31,32]$. In addition, elevated uric acid may modestly increase the risk of stroke morbidity and mortality $[11,12]$. In this study, we adopted the classic threshold of 6 and $7 \mathrm{mg} / \mathrm{dL}$ SUA for women and men to define hyperuricemia. However, many recent studies indicate that a cardiovascular SUA threshold was significantly lower than that used for the classic definition of hyperuricemia [33, 34]. Thus, further researches are warranted to explore the combination of hypertension and hyperuricemia on ischemic stroke.

Both hypertension and hyperuricemia were positively associated with the risk of ischemic stroke. Results of our study also show that the combination of hypertension and hyperuricemia had more than ninefold higher risk than those without hypertension and hyperuricemia in women. However, the joint effect of hypertension and hyperuricemia was not observed in men. These findings showed that the interaction between hypertension and hyperuricemia was statistically significant only in women rather than in men after adjustment for age, current smoking, current drinking, BMI, TG, HDL-C and eGFR. The potential mechanism related to ischemic stroke might be arterial stiffness caused by the combination of hyperuricemia and hypertension [35, 36].

There are some reasons that may explain the gender differences in the joint effect of hypertension and hyperuricemia to ischemic stroke. Previous studies have shown that hyperuricemia was more relevant with hypertension in women than men $[37,38]$. In addition, the Apolipoprotein Mortality Risk Study suggested that uric acid was more strongly associated to stroke in women than in men [32]. Furthermore, according to a systematical review, individuals with moderate hypertension had a higher risk of stroke in women than in men [39]. Therefore, the gender differences in the joint effect of hypertension and hyperuricemia to ischemic stroke were reasonable.

This study still has several limitations that need to be noticed. Firstly, the cross-sectional design cannot prove the causality between hypertension, hyperuricemia, and ischemic stroke. Secondly, this study was conducted in rural areas of northeast China, which may produce selection bias. Thirdly, although a recent study showed that diuretic-related hyperuricemia had the same cardiovascular risk as nondiuretic-related hyperuricemia, the lack of information on diuretics may influence the outcome of serum uric acid and ischemic stroke in hypertensive patients [40]. Finally, 
we did not collect information about the history of stroke and related medicine.

\section{Conclusions}

This study demonstrated the positive correlations between hypertension, hyperuricemia and ischemic stroke in a rural Chinese population. More importantly, our study demonstrated the joint effect between hypertension and hyperuricemia towards ischemic stroke only in women, not in men. Our results suggest the joint effect of hypertension and hyperuricemia on ischemic stroke in women may be greater than the sum of their individual effects.

\begin{abstract}
Abbreviations
SD: Standard deviation; BMI: Body mass index; FPG: Fasting plasma glucose; TC: Total cholesterol; TG: Triglyceride; HDL-C: High-density lipoprotein cholesterol; LDL-C: Low-density lipoprotein cholesterol; eGFR: Estimated glomerular filtration rate; SBP: Systolic blood pressure; DBP: Diastolic blood pressure; SUA: Serum uric acid
\end{abstract}

\section{Acknowledgements}

We would like to express our gratitude to all those who exert their effects in achieving this study.

\section{Authors' contributions}

In this study, P Sun and M Chen did the study design, statistical analyses and results interpretation. Z Li, Y Zhou, S Yu, H Yang, G Sun, L Zheng and Y Sun participated as analyzing and resolving difficulties of analytic strategies and results discussion. Finally, X Guo functioned as final reviewer and corresponding author. All authors read and approved the final manuscript.

\section{Funding}

This study was funded by National Natural Science Foundation of China (Grant \# 81800361), National Key R\&D Program of China (Grant \#2017YF(1307600), and the National Key Research and Development Program from the Ministry of Science and Technology of China (Project Grant \# 2018YFC1312400, Sub-project Grant \# 2018YFC1312403).

\section{Availability of data and materials}

The datasets generated during and analysed during the current study are not publicly available due to individual privacy concerns but are available from the corresponding author on reasonable request.

\section{Declarations}

\section{Ethics approval and consent to participate}

This study was conducted in compliance with the ethical principle of the Declaration of Helsinki. All participants provided written informed consent and all procedures were performed in accordance with the ethical standards. The study protocol was approved by the Ethics Committee of China Medical University (Shenyang, China).

\section{Consent for publication}

All co-authors and participants have been informed and given their consent for publication of this article.

\section{Competing interests}

The authors declare that they have no competing interests.

\section{Author details}

'Department of Ophthalmology, the First Hospital of China Medical University, Shenyang, Liaoning, China. ${ }^{2}$ Department of Cardiology, the First Hospital of China Medical University, 155 Nanjing North Street, Heping District, Shenyang 110001, Liaoning, China. ${ }^{3}$ Department of Clinical Epidemiology, Library, Shengjing Hospital of China Medical University, Shenyang, Liaoning, China.
Received: 7 November 2020 Accepted: 22 January 2021

Published online: 23 April 2021

\section{References}

1. Krishnamurthi R, Feigin V, Forouzanfar M, Mensah G, Connor M, Bennett D, et al. Global and regional burden of first-ever ischaemic and haemorrhagic stroke during 1990-2010: findings from the global burden of disease study 2010. Lancet Glob Health. 2013;1(5):e259-81. https://doi.org/10.1016/ S2214-109X(13)70089-5.

2. Zhou M, Wang H, Zhu J, Chen W, Wang L, Liu S, et al. Cause-specific mortality for 240 causes in China during 1990-2013: a systematic subnational analysis for the global burden of disease study 2013. Lancet (London, England). 2016;387(10015):251-72.

3. Liu L, Wang D, Wong KS, Wang Y. Stroke and stroke care in China: huge burden, significant workload, and a national priority. Stroke. 2011;42(12): 3651-4. https://doi.org/10.1161/STROKEAHA.111.635755.

4. Miller J, Kinni H, Lewandowski C, Nowak R, Levy P. Management of hypertension in stroke. Ann Emerg Med. 2014;64(3):248-55. https://doi.org/1 0.1016/j.annemergmed.2014.03.004.

5. Niska R. Blood pressure measurements at emergency department visits by adults: United States. NCHS data brief. 2007-2008;2011(72):1-8.

6. Anderson C, Heeley E, Huang Y, Wang J, Stapf C, Delcourt C, et al. Rapid blood-pressure lowering in patients with acute intracerebral hemorrhage. $\mathrm{N}$ Engl J Med. 2013;368(25):2355-65. https://doi.org/10.1056/NEJMoa1214609.

7. Ishitsuka K, Kamouchi M, Hata J, Fukuda K, Matsuo R, Kuroda J, et al. High blood pressure after acute ischemic stroke is associated with poor clinical outcomes: Fukuoka Stroke Registry. Hypertension (Dallas, Tex : 1979). 2014; 63(1):54-60.

8. Kannel W, Wolf P, Verter J, McNamara P. Epidemiologic assessment of the role of blood pressure in stroke. The Framingham study. JAMA. 1970;214(2): 301-10.

9. Kannel W, Wolf P, McGee D, Dawber T, McNamara P, Castelli W. Systolic blood pressure, arterial rigidity, and risk of stroke. The Framingham study. JAMA. 1981;245(12):1225-9.

10. $L W, W H, D M, Q Z, C W, E P, M ~ W$. Relationship between serum uric acid and ischemic stroke in a large type 2 diabetes population in China: A crosssectional study. J Neurol Sci. 2017;376:176-80. https://doi.org/10.1016/j.jns.2 017.03.023.

11. Kim S, Guevara J, Kim K, Choi H, Heitjan D, Albert D. Hyperuricemia and risk of stroke: a systematic review and meta-analysis. Arthritis Rheum. 2009;61(7): 885-92. https://doi.org/10.1002/art.24612.

12. Li M, Hou W, Zhang X, Hu L, Tang Z. Hyperuricemia and risk of stroke: a systematic review and meta-analysis of prospective studies. Atherosclerosis. 2014:232(2):265-70. https://doi.org/10.1016/j.atherosclerosis.2013.11.051.

13. Johnson RJ, Kang DH, Feig D, Kivlighn S, Kanellis J, Watanabe S, et al. Is there a pathogenetic role for uric acid in hypertension and cardiovascular and renal disease? Hypertension. 2003;41(6):1183-90. https://doi.org/10.11 61/01.HYP.0000069700.62727.C5.

14. Nakanishi N, Okamoto M, Yoshida H, Matsuo Y, Suzuki K, Tatara K. Serum uric acid and risk for development of hypertension and impaired fasting glucose or type II diabetes in Japanese male office workers. Eur J Epidemiol. 2003;18(6):523-30. https://doi.org/10.1023/a:1024600905574.

15. Feig D, Kang D, Johnson R. Uric acid and cardiovascular risk. N Engl J Med. 2008;359(17):1811-21. https://doi.org/10.1056/NEJMra0800885.

16. Guo X, Li Z, Guo L, Zheng L, Yu S, Yang H, et al. An update on overweight and obesity in rural Northeast China: from lifestyle risk factors to cardiometabolic comorbidities. BMC Public Health. 2014;14(1):1046. https:// doi.org/10.1186/1471-2458-14-1046

17. Chen $M-Q$, Shi W-R, Shi C-N, Zhou Y-P, Sun Y-X. Impact of monocyte to high-density lipoprotein ratio on prevalent hyperuricemia: findings from a rural Chinese population. Lipids Health Dis. 2020;19(1):48. https://doi.org/1 0.1186/s12944-020-01226-6.

18. Levey AS, Stevens LA, Schmid CH, Zhang YL, Castro AF 3rd, Feldman HI, et al. A new equation to estimate glomerular filtration rate. Ann Intern Med. 2009; 150(9):604-12. https://doi.org/10.7326/0003-4819-150-9-200905050-00006.

19. PHF G, ERM S. Pharmacotherapy for hyperuricemia in hypertensive patients. Cochrane Database Syst Rev. 2017:4:Cd008652.

20. Chobanian AV, Bakris GL, Black HR, Cushman WC, Green LA, Izzo JL Jr, et al. The seventh report of the joint National Committee on prevention, detection, evaluation, and treatment of high blood pressure: the JNC 7 report. JAMA. 2003; 289(19):2560-72. https://doi.org/10.1001/jama.289.19.2560. 
21. Gąsecki D, Coca A, Cunha P, Hering D, Manios E, Lovic D, et al. Blood pressure in acute ischemic stroke: challenges in trial interpretation and clinical management: position of the ESH working group on hypertension and the brain. J Hypertens. 2018;36(6):1212-21. https://doi.org/10.1097/HJH.0000000000001704.

22. Alloubani A, Saleh A, Abdelhafiz I. Hypertension and diabetes mellitus as a predictive risk factors for stroke. Diabetes \& metabolic syndrome. 2018;12(4): 577-84. https://doi.org/10.1016/j.dsx.2018.03.009.

23. Lackland DT, Voeks JH, Boan AD. Hypertension and stroke: an appraisal of the evidence and implications for clinical management. Expert Rev Cardiovasc Ther. 2016;14(5):609-16. https://doi.org/10.1586/14779072.2016.1143359.

24. Potter JF, Robinson TG, Ford GA, Mistri A, James M, Chernova J, et al. Controlling hypertension and hypotension immediately post-stroke (CHHI PS): a randomised, placebo-controlled, double-blind pilot trial. Lancet Neurol. 2009;8(1):48-56. https://doi.org/10.1016/S1474-4422(08)70263-1.

25. Schrader J, Lüders S, Kulschewski A, Berger J, Zidek W, Treib J, et al. The ACCESS study: evaluation of acute candesartan Cilexetil therapy in stroke survivors. Stroke. 2003;34(7):1699-703. https//doi.org/10.1161/01.STR.0000075777.18006.89.

26. Wallace JD, Levy LL. Blood pressure after stroke. Jama. 1981;246(19):2177-80 https://doi.org/10.1001/jama.1981.03320190035023.

27. Leonardi-Bee J, Bath PM, Phillips SJ, Sandercock PA. Blood pressure and clinical outcomes in the international stroke trial. Stroke. 2002;33(5):1315-20. https://doi.org/10.1161/01.STR.0000014509.11540.66.

28. Willmot M, Leonardi-Bee J, Bath PM. High blood pressure in acute stroke and subsequent outcome: a systematic review. Hypertension. 2004;43(1):1824. https://doi.org/10.1161/01.HYP.0000105052.65787.35.

29. Chu NF, Wang DJ, Liou SH, Shieh SM. Relationship between hyperuricemia and other cardiovascular disease risk factors among adult males in Taiwan. Eur J Epidemiol. 2000;16(1):13-7. https://doi.org/10.1023/A:1007654507054.

30. Bos MJ, Koudstaal PJ, Hofman A, Witteman JC, Breteler MM. Uric acid is a risk factor for myocardial infarction and stroke: the Rotterdam study. Stroke. 2006;37(6):1503-7. https://doi.org/10.1161/01.STR.0000221716.55088.d4.

31. Holme I, Aastveit AH, Hammar N, Jungner I, Walldius G. Uric acid and risk of myocardial infarction, stroke and congestive heart failure in 417,734 men and women in the Apolipoprotein MOrtality RISk study (AMORIS). J Intern Med. 2009;266(6):558-70. https://doi.org/10.1111/j.1365-2796.2009.02133.x.

32. Zhang W, Iso H, Murakami Y, Miura K, Nagai M, Sugiyama D, et al. Serum uric acid and mortality form cardiovascular disease: EPOCH-JAPAN study. J Atheroscler Thromb. 2016;23(6):692-703. https://doi.org/10.5551/jat.31591.

33. Maloberti A, Giannattasio C, Bombelli M, Desideri G, Cicero AFG, Muiesan ML, et al. Hyperuricemia and risk of cardiovascular outcomes: the experience of the URRAH (uric acid right for heart health) project. High Blood Press Cardiovasc Prev. 2020;27(2):121-8. https://doi.org/10.1007/s40292-020-00368-Z.

34. Virdis A, Masi S, Casiglia E, Tikhonoff V, Cicero AFG, Ungar A, et al. Identification of the uric acid thresholds predicting an increased Total and cardiovascular mortality over 20 years. Hypertension. 2020;75(2):302-8. https://doi.org/10.1161/HYPERTENSIONAHA.119.13643.

35. Rebora P, Andreano A, Triglione N, Piccinelli E, Palazzini M, Occhi L, et al. Association between uric acid and pulse wave velocity in hypertensive patients and in the general population: a systematic review and meta-analysis. Blood Press. 2020;29(4):220-31. https://doi.org/10.1080/08037051.2020.1735929.

36. Maloberti A, Rebora P, Andreano A, Vallerio P, De Chiara B, Signorini S, et al. Pulse wave velocity progression over a medium-term follow-up in hypertensives: Focus on uric acid. J Clin Hypertension (Greenwich, Conn). 2019;21(7):975-83.

37. Kivity S, Kopel E, Maor E, Abu-Bachar F, Segev S, Sidi Y, et al. Association of serum uric acid and cardiovascular disease in healthy adults. Am J Cardiol. 2013;111(8):1146-51. https://doi.org/10.1016/j.amjcard.2012.12.034.

38. Babio N, Martínez-González MA, Estruch R, Wärnberg J, Recondo J, Ortega-Calvo M, et al. Associations between serum uric acid concentrations and metabolic syndrome and its components in the PREDIMED study. Nutr Metab Cardiovasc Dis. 2015;25(2):173-80. https://doi.org/10.1016/j.numecd.2014.10.006.

39. Gorgui J, Gorshkov M, Khan N, Daskalopoulou SS. Hypertension as a risk factor for ischemic stroke in women. Can J Cardiol. 2014;30(7):774-82. https://doi.org/10.1016/.j.jca.2014.01.007.

40. Maloberti A, Bombelli M, Facchetti R, Barbagallo CM, Bernardino B, Rosei EA, et al. Relationships between diuretic-related hyperuricemia and cardiovascular events: data from the URic acid right for heArt health study. J Hypertens. 2021; 39(2):333-40. https://doi.org/10.1097/HJH.0000000000002600.

\section{Publisher's Note}

Springer Nature remains neutral with regard to jurisdictional claims in published maps and institutional affiliations.

Ready to submit your research? Choose BMC and benefit from:

- fast, convenient online submission

- thorough peer review by experienced researchers in your field

- rapid publication on acceptance

- support for research data, including large and complex data types

- gold Open Access which fosters wider collaboration and increased citations

- maximum visibility for your research: over $100 \mathrm{M}$ website views per year

At $\mathrm{BMC}$, research is always in progress.

Learn more biomedcentral.com/submissions 